\title{
Personificación e iconografía de la muerte en la Grecia antigua
}

\author{
Personification and iconography of death in ancient Greece \\ Emilio Crespo Güemes ${ }^{1}$
}

Fecha de recepción: 06-01-2020

Fecha de aceptación: 22-09-2020

\begin{abstract}
Resumen
El presente artículo reúne las menciones y representaciones de la personificación de la Muerte en la literatura y en las artes plásticas desde Homero hasta el comienzo de la época helenística. Centra la atención en la Ilíada de Homero, en la Teogonía de Hesíodo, en la tragedia y en la célebre cratera pintada por Eufronio, que representa el momento en que la Muerte y el Sueño, en presencia de Hermes, levantan del suelo el cadáver de Sarpedón para transportarlo a su tierra natal. El artículo sostiene que la escena del traslado mítico del cuerpo de Sarpedón por el Sueño y la Muerte se reinterpretó como la repatriación del cadáver de cualquier ciudadano ateniense muerto por la patria en el extranjero, que la ley mencionada por Tucídides en su Historia de la guerra del Peloponeso imponía.
\end{abstract}

Palabras clave: Muerte, personificación, iconografía, Grecia antigua, literatura, artes plásticas

\begin{abstract}
This article brings together mentions and representations of the personification of Death in literature and the visual arts from Homer to the beginning of the Hellenistic era. It focuses on Homer's Iliad, Hesiod's Theogony, tragedy and the famous crater painted by Euphronios, which represents the moment when Death and Sleep, in the presence of Hermes, raise Sarpedon's corpse from the ground to transport it to his native land. The article argues that the scene of the mythical transfer of Sarpedon's body by Death and Sleep was reinterpreted as the repatriation of the body of any Athenian citizen who had died abroad in fight for the homeland, which the law mentioned by Thucydides in his History of the Peloponnesian War imposed.
\end{abstract}

Keywords: Death, personification, iconography, Ancient Greece, literature, visual art

\footnotetext{
1 Docente Catedrático Emérito en Filología Griega. Doctor en Filología Clásica. Universidad Autónoma de Madrid, España. Doctor honoris causa por la Universidad Aristóteles de Salónica, Grecia. Correo electrónico: emilio.crespo@uam.es
} 


\section{Introducción ${ }^{2}$}

Estas páginas tratan sobre la personificación y la iconografía de la muerte en la literatura y en las artes plásticas desde Homero hasta la época helenística, centrando la atención en la Ilíada y en la cratera pintada por Eufronio, que representa el momento en que la Muerte y el Sueño, en presencia de Hermes, levantan el cadáver de Sarpedón, que había combatido en Troya como aliado de los troyanos, para transportarlo a Licia ${ }^{3}$.

Mi objetivo es reconstruir la evolución por la que la iconografía de la muerte emergió en el siglo VI a.C. y desapareció en el siglo IV a.C. Distinguiremos los siguientes hitos: la iconografía de la muerte surgió a partir de la representación del traslado del cadáver de Sarpedón relatado en la Ilíada; la iconografía de la repatriación del cadáver de Sarpedón se convirtió en un símbolo del sacrificio por la patria ateniense para representar el momento en que los familiares depositaban en la tumba el cadáver de un ser querido que, como Sarpedón, había muerto en el extranjero y cuyos restos habían sido repatriados a Atenas; finalmente, el cambio de las condiciones sociopolíticas que habían conducido a la difusión de la representación del momento en que el cadáver era trasladado condujeron a la desaparición de la iconografía de la muerte.

La muerte aparece ya personificada en la Ilíada de Homero y en la Teogonía de Hesíodo, pero estas obras no indican su aspecto exterior ni su indumentaria. Las representaciones más antiguas de la Muerte que se han conservado son muy posteriores: un fragmento de copa firmada por Eufronio como alfarero hacia 520 a.C. (figura 1), y la célebre cratera de cáliz decorada con figuras rojas firmada también por Eufronio como pintor hacia 515 a.C. (figura 2). Tanto en la copa como en la cratera, la Muerte y el Sueño aparecen como guerreros que solo se diferencian por la inscripción que acompaña el nombre de cada uno: ambos tienen alas en la cratera, pero no en la copa, y ambos tienen barba y panoplia consistente en casco, coraza y grebas ${ }^{4}$. En algunas vasijas posteriores la Muerte se distingue del Sueño por tener piel blanca y barba.

Esta imagen de la Muerte, creada probablemente por Eufronio, se mantuvo con leves variaciones hasta el siglo IV a.C. en pintura sobre cerámica y en esculturas, pero no pervivió en las artes plásticas helenísticas y romanas. Las razones de su desaparición son varias, entre las cuales una es puramente iconográfica: la imagen de la Muerte en el vaso de Eufronio, en la medida en que representa un héroe muerto en batalla, difícilmente podía expresar la muerte humana en general. Además, la Muerte es una figura secundaria en la escena. Otras causas históricas, religiosas y comerciales debieron de contribuir a la desaparición de esta imagen de la muerte.

Como es sabido, la iconografía que se impuso desde el Renacimiento en la tradición occidental y permanece en la actualidad presenta la Muerte como un esqueleto humano en movimiento, que en la mayor parte de las representaciones lleva una guadaña y en algunas una tuba5.

2 Este artículo fue realizado con la ayuda económica del Gobierno de España a través del Proyecto de Investigación FFI2015-65541-C3-1-P.

3 Para un catálogo de representaciones iconográficas de la Muerte véase especialmente LIMC s.v. Thanatos (artículo de J. Bažant); Shapiro (1991, 1993, 1994). Elvira Barba (2008, pp. 315-7) dedica una breve pero útil sección a la iconografía de la muerte y del sueño.

$4 \quad$ En la copa ambos tienen también, escudo y espada.

5 Algunos ejemplos aparecen en las siguientes obras: el Tríptico de la vanidad terrestre y de la salvación divina, de H. Memling (sobre madera, hacia 1485; Musée des Beaux- Arts, Estrasburgo), está compuesto de tres paneles pintados por ambas caras, de los que el central representa una mujer desnuda que se mira a un espejo y los laterales representan la Muerte y el Demonio; La Muerte, de Gil de Ronza (1523, Museo Nacional de Escultura Colegio de San Gregorio (Valladolid); y El triunfo de la Muerte de Pieter Brueghel el Viejo (óleo, 1562-3, Museo del Prado), que representa un ejército de esqueletos que arrasa la tierra. Cf. también M. de Cervantes, Don Quijote de la Mancha, segunda parte, capítulo 20: "[La Muerte n]o es segador que duerme las siestas, que a todas horas siega". 
La personificación de la Muerte como esqueleto humano, ocasional en época del Imperio romano, solo se difundió en el Renacimiento ${ }^{6}$.

\section{El Sueño y la Muerte como personificaciones}

La personificación consiste en atribuir características personales a una entidad no personal. El género gramatical del sustantivo que designa el concepto personificado condiciona el sexo atribuido a la personificación y, en consecuencia, su aspecto exterior. Así, tanto Hýpnos (Sueño) como Thánatos (Muerte), a los que se hace referencia mediante sustantivos de género masculino en griego, son personificados como varones.

Las personificaciones tienen una naturaleza, un grado de fijación y un número variable de propiedades humanas (Shapiro 1993, p. 15). Todas tienen un nombre que designa un evento o una experiencia humana, o una propiedad (como la Inmortalidad o la Justicia), o una entidad o fenómeno natural (como el Sol y la Noche). Los nombres de los dioses también se emplean para simbolizar experiencias humanas, propiedades o cuerpos o fenómenos naturales, pero las personificaciones se diferencian de los nombres de dioses en que el sustantivo que designa aquellas evoca de modo primario una experiencia humana o una entidad no personal o una propiedad, mientras que el nombre de estos evoca en primer término un dios. Así, mientras que Bía ('Violencia') es la personificación de la violencia, Ares (o Marte) es un dios que simboliza la violencia y la agresividad. La Muerte pertenece al grupo de personificaciones que podría designar una experiencia de los seres vivos, pero se centra en la muerte humana?.
En segundo lugar, las personificaciones son más o menos estables. Las más estables como Eris ('Disputa') y Eros ('Amor') actúan en mitos y reciben culto religioso (o al menos una de las dos cosas), pero las menos estables (como Phobos 'Huida' y Deimos 'Temor'), denominadas tradicionalmente Augenblicksgötter 'dioses momentáneos', no actúan en los mitos ni reciben culto religioso, o solo de manera ocasional. La mayoría tiene genealogía y, por tanto, pertenece a la mitología. Las que no fueron objeto de culto en la religión clásica, o solo lo recibieron en época tardía o de modo excepcional, no eran concebidas como dioses. Pausanias (Descripción de Grecia, 3.18.1) informa de que en la ciudadela de Esparta había imágenes de bulto redondo de la Muerte y del Sueño, pero no sabemos si la de la Muerte recibió culto. Aparte de esa, no hay otra mención de una estatua de la Muerte. Según Eurípides (Alcestis, 424), Thánatos es 'el implacable dios del inframundo'. Como la Muerte aparece personificada en la literatura y en las artes plásticas y tiene una genealogía mítica, pero no parece que recibiera culto, podemos considerarla una personificación mítica.

En tercer lugar, el número y cualidad de las propiedades humanas atribuido a las personificaciones varía. Algunas personificaciones adquieren características humanas adicionales en el curso de la historia. En el caso de la Muerte, la iconografía posterior evoluciona precisando rasgos que los poemas épicos arcaicos no expresan.

\section{La personificación de la Muerte en la Ilíada}

La Muerte (Thánatos) y el Sueño (Hýpnos) son hermanos según Homero, Ilíada 14.231, y Hesíodo, Teogonía 212 y 756 (también Pausanias, Descripción de Grecia 3.18.1); según

6 Aunque los romanos parecen no haberla representado, la Muerte aparece en un célebre mosaico de Pompeya procedente de las excavaciones del convento de San Gregorio en Roma como un esqueleto humano vuelto hacia el espectador acostado junto a su guadaña bajo la que se lee la

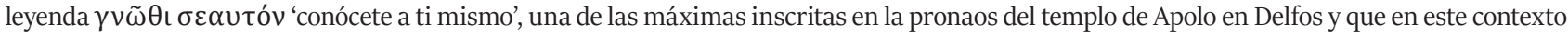
equivale probablemente a la máxima latina memento mori 'recuerda que vas a morir' (figura 14a). También se han publicado mosaicos que representan un esqueleto y un nombre de persona en griego, como el hallado en Turquía en un edificio del siglo III d.C. (figura 14b).

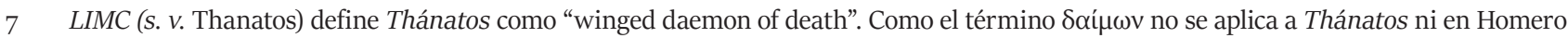
ni en Hesíodo, prescindimos de este uso. 
Ilíada 16.672 y 682, son hermanos gemelos ${ }^{8}$. Como el Sueño se refugió en la Noche (Il. 14.259 s.) en una ocasión en que Zeus lo quería castigar (14.231-354), es verosímil que la Noche sea la madre del Sueño en la Ilíada (como en la Teogonía de Hesíodo, según veremos más abajo). Aparte de estas brevísimas menciones de la Muerte, los dos hermanos juegan el papel secundario de trasladar el cadáver de Sarpedón a Licia cumpliendo la orden de Zeus que Apolo les transmite (Il. 16.419-683). Sarpedón era hijo de Zeus, habitaba en Licia y había llegado a Troya como aliado de los troyanos. Patroclo lo mató en la batalla alcanzándolo con un proyectil en el corazón (477-481). Zeus entonces ordenó a Apolo hacer que el Sueño y la Muerte transportaran el cadáver a Licia para enterrarlo. Apolo, cumpliendo la orden, sacó de la batalla el cadáver de Sarpedón y se lo entregó a la Muerte y al Sueño para que lo transportaran a Licia (Il. 16.676-683):

Así habló, y Apolo no desoyó la orden de su padre,

Y descendió de los montes del Ida a la atroz contienda.

Y tras sacar de los proyectiles el cuerpo del divino Sarpedón,

Lo llevó muy lejos y lo bañó en las corrientes del río.

Ungió su cuerpo con ambrosía y lo vistió con inmortales ropas.

Y lo envió luego para que lo llevaran ante los raudos escoltas,

El Sueño y la Muerte, hermanos gemelos, quienes pronto

Lo depositaron en el pingüe pueblo de la vasta Licia.

El episodio de Sarpedón tiene importancia porque narra la muerte del único hijo de Zeus que combate en el bando de los troyanos y porque el destino, que ha dictado la muerte de Sarpedón, a primera vista prevalece sobre la voluntad de Zeus, que desea su vida. Cuando Patroclo y Sarpedón van a enfrentarse, el soberano de los dioses olímpicos lamenta que el destino haya decretado la muerte de este a manos de Patroclo, pero duda si evitar la muerte de su hijo (433-438). Hera le aconseja aceptar el destino y dejarlo sucumbir. Le previene de que, si no lo hace, los demás dioses lo desaprobarán y le recomienda enviar a la Muerte y al Sueño para que transporten su cadáver a
Licia (440-457). Zeus sigue el consejo de Hera, los aqueos logran rescatar el cadáver, y Apolo ordena a la Muerte y al Sueño que trasladen el cadáver a Licia. Cabe preguntarse si Zeus, de haberse opuesto al destino, habría triunfado sobre la parca, pero su decisión final es someterse a lo dispuesto por el hado. De manera análoga, los héroes homéricos tienen libre albedrío porque deciden, pero siempre deciden lo que el destino dispone.

\section{La personificación de la Muerte en la Teogonía}

La Teogonía de Hesíodo menciona la Muerte y el Sueño como hijos de la Noche en dos pasajes. En el primero (Teogonía 211-213), la lista de los primeros hijos de la Noche incluye tres grupos formados por el Hado (Móros), la Destrucción (Ker) y la Muerte (Thánatos), el Sueño (Hýpnos) y la tribu de los Ensueños. El segundo menciona las criaturas que habitan bajo tierra en el Tártaro frente a la morada de Hades (Teogonía 756-766):

Ella lleva en brazos el Sueño, hermano de la Muerte,

La Noche maldita, oculta por una nube brumosa.

Allí tienen su casa los hijos de la oscura Noche,

Sueño y Muerte, dioses terribles. Nunca los

Alumbra el radiante Sol con sus rayos,

Ni al subir al cielo ni al bajar del cielo.

El uno la tierra y los anchos lomos del mar

Recorre tranquilo y es dulce para los hombres.

La otra tiene corazón de hierro y entrañas de bronce

Implacables en el pecho. Retiene al que coge primero

De los hombres y es odiosa hasta para los inmortales dioses.

La Noche lleva en brazos a Hýpnos (Sueño), lo que implica que es un niño. De Thánatos (Muerte), su hermano, no se indica si es niño o adulto, aunque sería niño si era hermano gemelo, como en la Ilíada.

8 Como la idea de que la Muerte y el Sueño son hermanos gemelos está aislada, es probable que 'gemelos' subraye simplemente la afinidad fraternal, no que realmente sean gemelos (cf. Janko 1992: ad 16.669-73). La afinidad del Sueño y de la Muerte explica que se diga que un guerrero al morir "se acostó para un broncíneo sueño" (Il. 11.241), expresión en la que ‘broncíneo' tiene el sentido de 'irrompible', frecuente en Homero. Thánatos es en un sentido más débil que Hýpnos, porque este doblega a los dioses, pero aquel no. Por eso Hera saluda al Sueño llamándolo 'soberano de todos los dioses y todas las gentes' (Il. 14.233). 
Como veremos enseguida, el Sueño aparecía como un niño en la representación más antigua de la que tenemos noticia, que no se ha conservado.

Como es habitual en la mitología clásica, la genealogía que Hesíodo atribuye a la Muerte se repite en autores posteriores (Higino, fab. praef; Cicerón, nat. 3.44; Pausanias 5.18.1). Por su parte, Sofócles hace a la Muerte y al Sueño hijos de la Tierra y del Tártaro y califica a Thánatos como "dador de sueño eterno" (OC 1574-1577).

\section{La primera representación (no conservada) de la Muerte}

Pausanias (Descripción de Grecia 5.17.5-19.10) describe con detalle el arca de Cípselo, en la que su madre ocultó al niño recién nacido para protegerlo de los Baquíadas y que más tarde fue tirano de Corinto desde 657 hasta 625 a.C. Los descendientes de Cípselo ofrendaron el arca en el templo de Hera en Olimpia, donde Pausanias la vio. Estaba hecha de cedro y decorada con figuras labradas en marfil, oro o sobre el propio cedro, y había inscripciones sobre la mayoría de las figuras. Entre ellas se encontraba una mujer que en su brazo derecho sostenía un niño blanco que dormía, y en el otro un niño negro que parecía dormir. El texto de Pausanias admite varias interpretaciones, en todas las cuales Sueño y Muerte forman una pareja antitética: uno era blanco y otro negro; uno estaba dormido y otro dormido en apariencia; uno tenía los pies a la derecha y otro a la izquierda. Las inscripciones explican -continúa Pausanias- que el grupo representa la Muerte (Thánatos) y el Sueño (Hýpnos) con Noche (Nýx), nodriza de ambos, pero no serían necesarias. Esta nota sugiere que la imagen de la Muerte y del Sueño en el arca de Cípselo se repetía en otras obras. Según Hesíodo, la Noche es la madre del Sueño y de la Muerte, y según Pausanias su nodriza; ambas cosas son compatibles. Este es el único caso en que Muerte y Sueño estaban representados como niños, como al menos el Sueño aparece en la Teogonía.

\section{La muerte de Sarpedón en la copa y en la cratera de Eufronio}

Las más antiguas representaciones de la Muerte y del Sueño conservadas aparecen en el fragmento de una copa ( $k$ ýlix) y en una cratera firmadas por Eufronio, destacado pintor ático de la primera generación de pintores de vasijas cerámicas que adoptaron la técnica de figuras rojas abandonando la de figuras negras. Eufronio fue también uno de los primeros pintores de vasijas cerámicas que firmó sus obras. La copa se data hacia 520 y la cratera hacia 515 a.C. De la más antigua, firmada por Eufronio como alfarero, solo se conserva un fragmento (figura 1) ${ }^{9}$. En ella, el Sueño y la Muerte (sin alas, barbados, con casco, grebas, coraza, espada y escudo) transportan el cuerpo de Sarpedón en procesión guiada por Acamante. Las figuras están identificadas por inscripciones con sus nombres.

La otra es una cratera de cáliz conservada completa. Está firmada por Eufronio como pintor y por Euxiteo como alfarero, lo que hace suponer que ambos la consideraron una creación de calidad (figura 2). Tiene la inscripción Léagros kalós ('Leagro es guapo'), que también aparece en otras vasijas pintadas por Eufronio. Fue hallada en 1972 en una tumba etrusca próxima a Cerveteri (Italia). Se trata, por tanto, de una vasija ática importada para decorar una tumba etrusca. Se exhibió hasta 2008 en el Metropolitan Museum de Nueva York y en la actualidad se expone en el museo arqueológico de Cerveteri, tras el acuerdo entre el Metropolitan Museum y el Gobierno de Italia para combatir el tráfico ilícito de bienes patrimoniales, una vez demostrado que el comerciante que la había vendido la había adquirido de modo ilegal.

Enmarcada por florituras en los bordes superior e inferior del cuerpo del vaso, el anverso representa en primer plano el cadáver de Sarpedón despojado de las armas y desnudo. El cuerpo, con varias heridas, está sostenido a un lado por el Sueño y al otro por la Muerte. Ambos tienen alas y barba y están protegidos por casco, coraza y grebas. En el centro y en segundo plano, Hermes, ataviado con el caduceo (bastón de heraldo), el pétaso (sombrero de ala ancha con alas) y sandalias aladas, en su condición de

9 El fragmento pertenece a una kýlix ática de figuras rojas atribuida al pintor Eufronio que estuvo en Dallas en la colección Nelson Bunker Hunt. Shapiro (1993, núm. 66; 1994. pp. 20-24); LIMC s.v. Sarpedon 3*). 
guía y acompañante del alma del cadáver (psicopompo), está presto a acompañar la comitiva. Los extremos están ocupados por guerreros en pie, armados con lanza, escudo y casco. Las figuras están identificadas por los siguientes nombres: Laodamante, Hýpnos, Hermes, Thánatos, Sarpedón, Hipólito.

El reverso muestra una escena de la vida cotidiana, no del mito: varios jóvenes, llamados Hipéroco, Hípaso, Megon, Acasto y Axipo, según indican los nombres pintados junto a cada figura, aparecen armados o armándose (figura 3). El estilo de las figuras de ambas caras es semejante, pero las del reverso fueron pintadas con más premura, antes de que se secara la arcilla. El pintor reunió en una misma cratera el pasado mítico y el presente, seguramente porque concebía ambas escenas como complementarias y aspectos de una sola realidad que se ilumina recíprocamente.

La coincidencia del tema y de varios detalles en el relato de la Ilíada y en la representación de la cratera de Eufronio prueba que la escena pintada sobre el anverso está basada en el relato de la Ilíada. La Muerte y el Sueño están presentes en ambas y en ambas alzan el cadáver de Sarpedón. Además, el chorro de sangre que brota del corazón del guerrero muerto en la representación se corresponde con la herida en el corazón que menciona la Ilíada (16.479-481):

Después arremetió con el bronce

Patroclo, y de su mano no escapó en vano el proyectil, que le acertó donde los pulmones encierran el musculado corazón.

La Ilíada relata que Apolo sacó los proyectiles del cuerpo de Sarpedón antes de encargar a la Muerte y al Sueño el traslado, lo que se corresponde con el hecho de que en la cratera el cadáver de Sarpedón ya no tiene proyectiles clavados en su cuerpo.
Sin embargo, hay diferencias menores entre la Ilíada y la representación en la cratera de Eufronio. En la Ilíada, es Apolo quien cumple la orden de Zeus de encargar a la Muerte y al Sueño que transporten el cadáver de Sarpedón a Licia, mientras que en la cratera de Eufronio es Hermes el que en su condición de psicopompo ('guía en el viaje del alma al Hades') preside la escena. En la Ilíada, Patroclo entregó las armas de Sarpedón a sus compañeros para que las llevaran a las naves (versos 663-665):

De los hombros de Sarpedón quitaron las armas

broncíneas, chispeantes, que el fornido hijo de Menecio dio a sus compañeros para que las llevaran a las cóncavas naves.

Apolo vistió a Sarpedón antes de entregarlo al Sueño y a la Muerte, mientras que, en la cratera de Eufronio, el cadáver de Sarpedón está todavía desnudo y despojado de las armas en el momento en que la Muerte y el Sueño lo levantan. Los guerreros que ocupan los extremos de la escena de la cratera no aparecen en la Ilíada. Probablemente, las diferencias no se deben a que Eufronio siguiera una versión diferente de la Ilíada, sino que modificó estos detalles para adaptar el relato a la representación iconográfica y visualizar el relato como una sola escena ${ }^{10}$. La presencia de Hermes en lugar de Apolo se justifica porque Hermes es el dios psicopompo que guía y acompaña a los muertos al infierno, mientras que la presencia de Apolo tiene una justificación interna en la Ilíada (Woodford 2003, p. 160 s.). La representación del cadáver desnudo, en lugar de vestido como en la Ilíada, visualiza que la muerte se produjo en la batalla y orienta la interpretación de la escena, al tiempo que refleja un momento previo del relato de la Ilíada. Los guerreros en los extremos enmarcan la escena ${ }^{11}$.

10 La kýlix ática de figuras rojas atribuida al pintor Nicóstenes, ca. 510 a.C. (figura 4; Museo Británico, E12, Shapiro 1993, pp. 134-135, núm. 68) presenta el mismo tema, pero el Sueño y la Muerte son jóvenes imberbes, lo que se extenderá en obras posteriores que representan el mismo tema. Uno tiene el pelo oscuro y otro claro. Además, Iris, a la izquierda, sustituye el papel que hace Hermes en la cratera de Eufronio.

11 La Ilíada no dice si la Muerte y el Sueño tienen alas, pero sí que son 'raudos' (16.671) y que lo transportarán 'rápidamente' (11.672), lo que se puede traducir visualmente en que tienen alas. La Ilíada tampoco dice que lleven o no lleven armas; que las lleven puede ser una invención de Eufronio. 


\section{Representaciones de la muerte en el siglo V a.C.}

La mayor parte de las representaciones de la Muerte y del Sueño en la cerámica del siglo V a.C. se encuentra en escenas que siguen de cerca la representada en la cratera de Eufronio, lo que da idea de su éxito. En algunas hay leves variaciones, que indican un deseo de innovación del artista o el desconocimiento de una iconografía más o menos fija en la tradición. Como veremos, la escena del traslado del cuerpo de Sarpedón es también frecuente en lécitos áticos de fondo blanco usados en el ámbito funerario, seguramente porque la escena adquirió un significado nuevo y simbolizaba la repatriación del cuerpo de un ciudadano ateniense muerto en acto de servicio a la patria en el extranjero para tributarle honras fúnebres en Atenas conforme a la ley tradicional (nómos pátrios) mencionada por Tucídides (Historia de la guerra del Peloponeso 2.34.1).

Entre las variaciones observadas, algunas vasijas representan el momento en que la Muerte y el Sueño depositan el cuerpo de Sarpedón en Licia, no el momento en que alzan el cadáver para transportarlo a Licia. A este respecto, hay que notar que en la tragedia perdida Europa o los Carios de Esquilo, Europa esperaba el retorno de su hijo Sarpedón en Licia, pero lo que la Muerte y el Sueño le traían era solo el cuerpo (Tragicorum Graecorum Fragmenta, vol. 4 pp. 217-222) ${ }^{12}$. Es probable que algunas vasijas que representan la escena en la que el Sueño y la Muerte deponen el cadáver en Licia evoquen la tragedia de Esquilo ${ }^{13}$.

Algunas representaciones muestran también un guerrero alado, de tamaño menor y con armas, que normalmente vuela sobre el cuerpo de Sarpedón. La investigación moderna denomina este "doble" que subsiste tras la muerte del hombre su eídolon ('imagen'), tomando la expresión utilizada en la Ilíada (23.72) y en la Odisea (24.14) para referirse a las almas de los muertos. Este es el caso de una jarra de cuello de terracota con figuras negras atribuida al pintor de Diosphos y conservada en el Museo del Louvre (F 388; figura 5; Shapiro 1993, núm. 71; LIMC Sarpedon $7^{\star}$ ), que procede de Capua y se data hacia 500-480. Los que alzan el cadáver son jóvenes, tienen alas y están armados con casco, grebas, coraza y espada ${ }^{14}$. Otra jarra (hýdria) de cuello del propio pintor de Diosphos, parecida pero decorada con figuras negras, que se expone en el Metropolitan Museum de Nueva York (56.171.25) y se data hacia 500 a.C. (figura 6, LIMC "Sarpedón 8*"; Shapiro 1993, núm. 70) presenta en la cara principal unos esbeltos Muerte y Sueño, uno barbado y otro no, sin alas, armados con lanza, casco, coraza y grebas, que alzan el cuerpo de Sarpedón, sobre el que está suspendida una figura más pequeña, que representa el eídolon. Junto a las figuras hay letras que no tienen sentido. El reverso representa a la Aurora (Eos) transportando el cadáver de su hijo Memnón, también muerto en la guerra de Troya. Cada cara de la jarra representa una escena en la que un aliado de los troyanos muerto en la guerra de Troya es trasladado al lugar de donde había llegado: Sarpedón a Licia, y Memnón a Etiopía.

Como en la jarra de figuras negras que acabamos de mencionar, otros vasos cerámicos relacionan la representación de las muertes de Sarpedón y de Memnón, cuyas leyendas presentan paralelismos cercanos. Así, la Muerte y el Sueño transportan el cadáver de Memnón en una copa ática de comienzos de s. V a.C. (Museo Nacional de Atenas 505, LIMC “Thanatos 13*”, Shapiro 1993, núm. 69), que representa una procesión encabezada por Hermes

12 Así, en la escena de LIMC "Sarpedon 12*” (430-420 a.C.), el Sueño y la Muerte con el cuerpo de Sarpedón están en presencia de ancianos licios. Además, sobre el cuerpo de Sarpedón aparece su eídolon (añadido en color blanco).

13 Shapiro (1993, pp. 138-139, núm. 72) interpreta un lécito de figuras negras y fondo blanco del museo de Frankfurt (que a veces se ha explicado como Eos ante el cadáver de Memnón aunque no es seguro que la figura sea femenina y, en todo caso, carece de alas) como Europa ante el cadáver de Sarpedón recién traído a Licia. En la tragedia de Esquilo citada el personaje principal era Europa. Este vaso no se menciona en LIMC s.v. Thánatos ni s.v. Sarpedon. Véase Shapiro 1994, p. 24.*

14 La cratera de cáliz atribuida al pintor de Eucárides que procede de Cerveteri (museo del Louvre (G 163; véase LIMC Sarpedon 6*; Shapiro 1993, pp. 140-141. y núm. 74) y se data en 490-480 a.C., representa el Sueño y la Muerte depositando el cadáver de Sarpedón en Licia. El Sueño y la Muerte aparecen como jóvenes desnudos e imberbes, a diferencia de la antigua representación de ambos como guerreros armados. Las figuras están identificadas por inscripciones. También aparece un eídolon alado que vuela hacia abajo. Esta imagen del Sueño y la Muerte como jóvenes desnudos es común en los lécitos funerarios áticos de la segunda mitad del siglo V a.C. 
psicopompo, que mira hacia atrás y va seguido por la Aurora, madre de Memnón, que se apoya sobre el cuerpo del difunto, transportado por la Muerte y el Sueño, para deponerlo con suavidad. Tras ellos marchan una figura femenina, que puede ser Iris, y otra masculina. El Sueño y la Muerte visten jitones, pero no están armados; solo uno tiene barba. La escena representada sobre el interior de una copa ( $k y ́ l i x)$ firmada por el pintor Duris que se data en 490-48o a.C. y que se conserva en el museo del Louvre de París (G 115) se llama comúnmente "Piedad de Memnón” (figura 7). La Aurora (Eos) levanta el cadáver de su hijo Memnón, que había llegado de Etiopía a Troya como aliado de los troyanos y fue muerto por Aquiles. La copa está firmada por Duris como pintor y por Calíades como alfarero. Como otras obras de Duris, tiene la leyenda pintada "Hermógenes guapo".

Desde aproximadamente 470 a.C. la escena del levantamiento del cadáver de Sarpedón pierde en algunos ejemplos, especialmente en lécitos áticos de fondo blanco datados a lo largo de la segunda mitad del siglo V a.C., detalles de la iconografía tradicional y se hace menos específica hasta el punto de que algunos ejemplares muestran simplemente dos figuras humanas masculinas desnudas y sin alas (una con barba y otra sin ella) que alzan o depositan un cadáver, en algunos casos junto a un túmulo funerario adornado con cintas, en el que hay un casco y otras armas ${ }^{15}$. Esta escena se puede interpretar como una versión poco específica del alzamiento del cadáver de Sarpedón o como una representación del momento en que los familiares deponen el cuerpo de un joven muerto en una campaña militar contemporánea. Es decir, la escena se ha desprendido de los detalles del mito y tiende a ser genérica y, por tanto, interpretable como contemporánea. La escena representada en el lécito de fondo blanco está aún más cargada de sentido si los allegados tributan honras fúnebres a alguien que había perdido la vida en el extranjero al servicio de la patria ateniense, como les sucedió a Sarpedón y a Memnón, y sus familiares habían repatriado el cadáver para darle sepultura (Shapiro 1994, p. 24; Díez de Velasco 1995, p. 34). Al propio tiempo, el pintor del vaso dota a un ser humano ordinario de status heroico. El mito engrandece experiencias de los mortales y, al revés, experiencias cotidianas iluminan el mito (cf. Woodford 2003, 162).

El lécito atribuido al pintor de Hypnos de Nueva York (440-430 a.C.) es muy fragmentario, pero conserva bien la policromía (figura 8; 23.16o.43a, b; LIMC, Thanatos 18*, Shapiro 1993, núm. 79). De la misma cronología es el lécito del British Museum (Catalogue D56; figura 9). También el lécito (Museo Británico D 58) atribuido al pintor de Thánatos (hacia 450 a.C.) representa a este más viejo, con barba y plumas en el cuerpo y al Sueño más joven, sin barba y piel roja oscura. Ambos están desnudos y transportan a un joven con coraza. La estela en el fondo está decorada con un escudo. El aspecto de la Muerte en este lécito parece estar basado en la iconografía de Caronte, que en esta época aparece como un hombre viejo con el pelo alborotado y barba. También la Muerte aparece con aspecto de Caronte y persiguiendo a una mujer en presencia de Hermes en el lécito del Louvre (CA 1264; LIMC, Thanatos $27^{\star}$ ) hallado en la tumba de una mujer. En los lécitos funerarios dedicados a mujeres la interpretación patriótica del ciudadano muerto en el extranjero no es posible, pero sí indican que la escena se ha transferido del mito a la realidad contemporánea ${ }^{16}$.

\section{La Muerte en la Alcestis de Eurípides}

La Muerte apareció como personaje solo en dos tragedias: en la Alcestis de Frínico (Tragicorum Graecorum Fragmenta, vol. I2 p. 73), que no se conserva, y en la de Eurípides, que ha llegado a nosotros y que es la tragedia más antigua conservada completa del tercer trágico ateniense, representada en 438 a.C. ocupando el lugar que normalmente estaba destinado al drama satírico. En ella, la Muerte hace una breve aparición (versos 28-

\footnotetext{
15 El ejemplar más antiguo del nuevo tipo es un lécito perteneciente al periodo anterior a la introducción de los lécitos polícromos de fondo blanco que se data en 470-46o a.C. y se expone en el Museo Nacional de Atenas (LIMC Thanatos 14*; Shapiro 1993, pp. 142-143. y núm. 75). El Sueño y la Muerte tienen alas adicionales pequeñas en los pies además de las tradicionales, están vestidos con túnicas y levantan el cuerpo de una muchacha muerta frente a una estela con cintas atadas a su alrededor.

16 Una curiosa representación de la Muerte (Thanatos 28*, Museo Británico E 155) aparece en la cara A de un kántharos, que muestra a Ixión con una espada arrodillándose ante un altar y atacado por una serpiente. Thánatos, desnudo y barbado con alas, saca a su víctima.
} 
76) en la parte dialogada del prólogo para conducir a Alcestis, esposa de Admeto que ha aceptado morir en lugar de él, a la morada de Hades. Se enfrenta a Apolo y lo acusa de haber delinquido por engañar a las diosas del destino e impedir que se cumpliera el destino de Admeto. El diálogo de la Muerte con Apolo da a entender que esta es poderosa porque lleva a todos los seres humanos al Hades, disfruta especialmente con la muerte de los jóvenes, es cruel e implacable porque no hace favores y odiosa para los mortales y para los dioses. El texto solo indica que es un personaje masculino, quizá alado y que porta espada.

\section{Iconografía de la Muerte en el siglo IV a.C.}

La mayor parte de las obras plásticas del siglo IV a.C. que representan la Muerte y que han llegado a nosotros proceden de fuera de la península Balcánica. Las representaciones sobre cerámica más destacadas proceden del sur de Italia y, probablemente, reflejan el mito del traslado del cadáver de Sarpedón según aparecía en tragedias que hallaron una nueva difusión en el siglo IV a.C. en las ciudades griegas del sur de la península Itálica. Una cratera de campana procedente de Apulia que pertenece al Metropolitan Museum de Nueva York (16.140; LIMC Sarpedon 14*; figura 10), de 400-380 a.C. presenta en el reverso a la Muerte y al Sueño, que vuelan transportando el cuerpo de Sarpedón hacia varias figuras que están de pie en el suelo mirando la llegada de los que traen el cuerpo de Sarpedón. Aunque existe la posibilidad (cf. LIMC s.v. Sarpedon) de que el personaje principal que está sentado sobre el trono sea Apolo, la interpretación de esta figura como Europa permite interpretar la escena como basada en la tragedia perdida de Esquilo titulada Europa o Carios (Taplin 2007, pp. 71-72). Un papiro conserva fragmentos de una alocución en la que probablemente Europa se jacta de haber tenido tres hijos de Zeus y de aguardar impaciente el regreso de Sarpedón, el menor. Por su parte, el anverso presenta una escena en el Olimpo, en la que quizá hay que identificar a Europa suplicando a Zeus por la vida de Sarpedón en presencia de Hera, Hýpnos y Pasithéa.
Una jarra (hýdria) lucania de figuras rojas de comienzos del siglo IV a.C. (LIMC, Sarpedon* 13; figura 11), que se exhibe en el Museo Nazionale della Siritide (Policoro), representa en el hombro la Muerte como un varón barbado y con serpientes en el pelo, que, junto con el Sueño, vuela trasladando el cuerpo de Sarpedón. Los personajes llevan inscripciones que los identifican. El cuerpo principal de la vasija representa cómo Patroclo, desnudo, clava la lanza a Sarpedón, ataviado con ropa licia, mientras Glauco acude en ayuda de Sarpedón. Es verosímil que la escena superior proceda también de la representación teatral en el sur de Italia (Taplin 2012, pp. 234-235).

También de la península Itálica procede el asa de cista de bronce que se expone en el Cleveland Museum of Arts 45.13 y que se data hacia 400 a.C. (LIMC, Sarpedon $15^{*}$; figura 12). Es obvio que el tema procede de Eufronio, pero el asa quizá represente al enterrado.

Finalmente, conviene mencionar el relieve de mármol del templo reciente de Ártemis de Éfeso que aparece sobre lo que quizá fue un tambor de una columna del templo. Aunque insegura (cf. LIMC s.v. Thanatos*31), la interpretación más probable es que las figuras representan a la Muerte guiando a Alcestis o a Eurídice hacia el inframundo acompañados por Hermes (figura 13).

\section{Conclusión}

Hemos visto que la Muerte aparece personificada raramente en la Ilíada de Homero y en la Teogonía de Hesíodo. Además, juega un papel secundario en el traslado del cadáver de Sarpedón a Licia en la Ilíada y hay referencias a ella como habitante de las profundidades del Tártaro. En la iconografía, hubo una representación de la Muerte y del Sueño como niños en brazos de la Noche. Pero la imagen más extendida de la muerte procede de la cratera pintada por Eufronio, en la que la Muerte y el Sueño aparecen como guerreros alados con casco, coraza y grebas. Con este aspecto debió de aparecer la Muerte en la tragedia conservada de Eurípides titulada Alcestis. Durante el siglo $V$ a.C. se observa que, especialmente en lécitos áticos de fondo blanco usados con fines funerarios, el traslado del cadáver de Sarpedón pierde los detalles más 
específicos y queda convertido en la representación del entierro de un ciudadano o, de manera aún más vaga, de una persona querida. Es muy verosímil que el traslado del cuerpo de Sarpedón, muerto en combate en el extranjero, convirtiera en una representación frecuente con una nueva interpretación patriótica cuando los atenienses instauraron la repatriación del cuerpo de los ciudadanos atenienses muertos en el extranjero al servicio de la patria para tributarles honras fúnebres públicas conforme al rito expuesto por Tucídides (Historia de la guerra del Peloponeso 2.34).

La imagen de la Muerte que fijó la iconografía del traslado del cadáver de Sarpedón no pervivió en las artes plásticas helenísticas y romanas. Las razones de su desaparición son desconocidas, pero podemos aventurar que la superstición, que evitaba incluso nombrar la muerte para no convocarla y, con más razón, evitaba también representarla, debió de jugar un papel importante.

Desde el Renacimiento al menos, la cultura occidental representa la Muerte mayoritariamente como un esqueleto humano en movimiento, que en la mayor parte de las representaciones lleva una guadaña. Esta representación es solo ocasional en época del Imperio Romano.

\section{Referencias bibliográficas}

Díez de Velasco Abellán, F. P. (1995). Los caminos de la muerte: religión, rito e iconografía del paso del más allá en la Grecia antigua, Madrid, Editorial Trotta

Elvira Barba, M. Á. (2008). Arte y mito. Manual de iconografía clásica, Madrid, Sílex

Janko, R. (1992). The Iliad: A Commentary, volume 4, books 13-16, Cambridge, CUP

LIMC = Lexicon Iconographicum Mythologiae Classicae, Zürich, München, Düsseldorf, Artemis \& Winkler Verlag, 1981-1999

Shapiro, H. A. (1991). "The Iconography of Mourning in Athenian Art", AJA 95,629-656
Shapiro, H. A. (1994). Myth into Art. Poet and Painter in Classical Greece, London \& New York, Routledge

Taplin, O. (2007). Plots and Plays: Interactions between Tragedy and Greek Vase-Painting of the Fourth Century B. C., Los Angeles, The J. Paul Getty Museum

Taplin, O. (2012). "How was Athenian Tragedy Played in the Greek West?" en Theater outside Athens. Drama in Greek Sicily and South Italy, ed. Kathryn Bosher, Cambridge, CUP, 226-249

Vermeule, E. (1979). Aspects of Death in Early Greek Art and Poetry, Berkeley - Los Angeles - London, University of Los Angeles Press

Woodford, S. (2003). Images of Myths in Classical Antiquity, Cambridge, CUP 


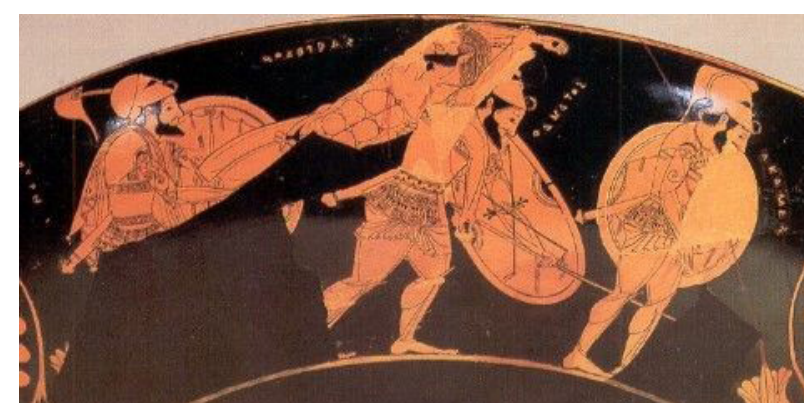

Figura 1

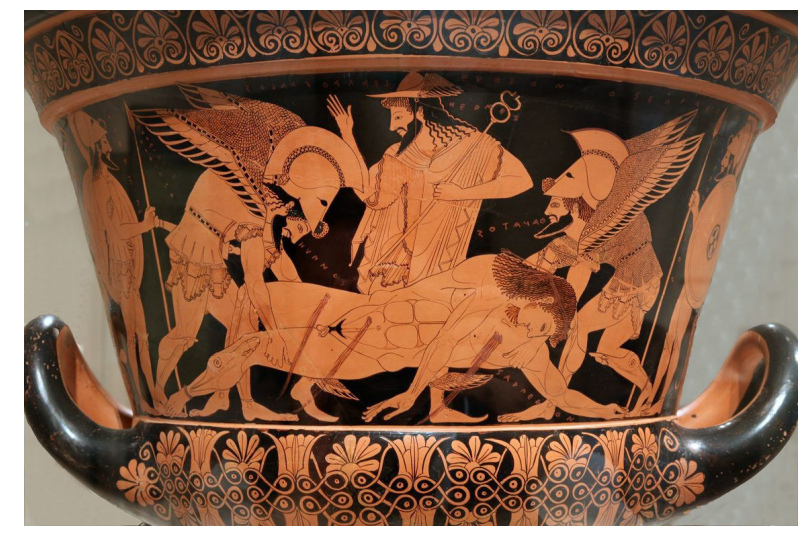

Figura 2

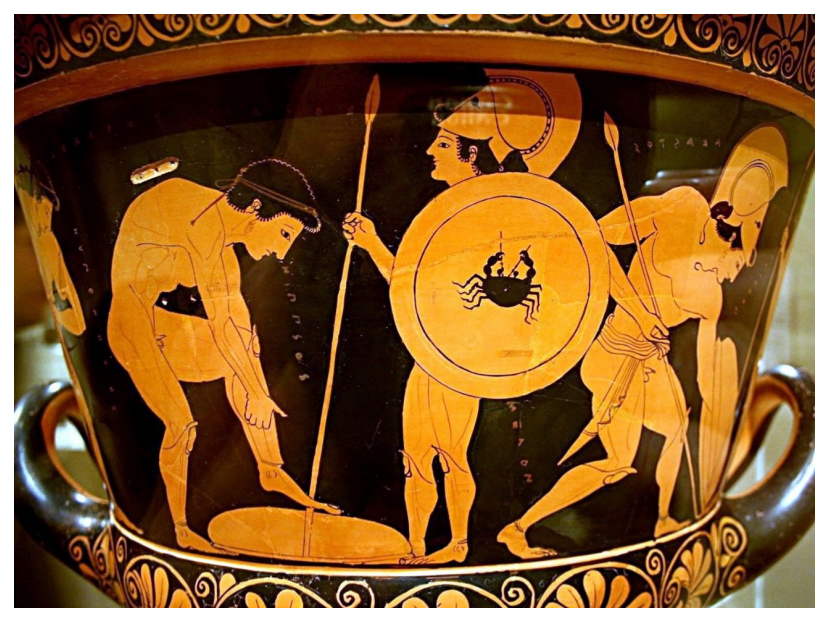

Figura 3

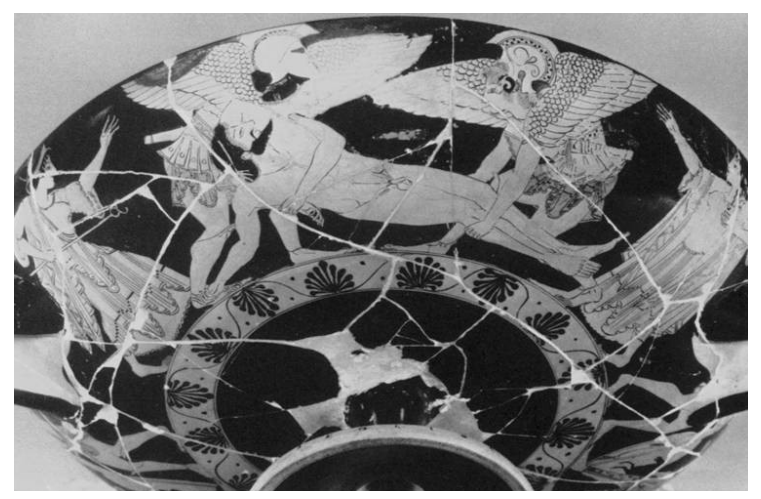

Figura 4

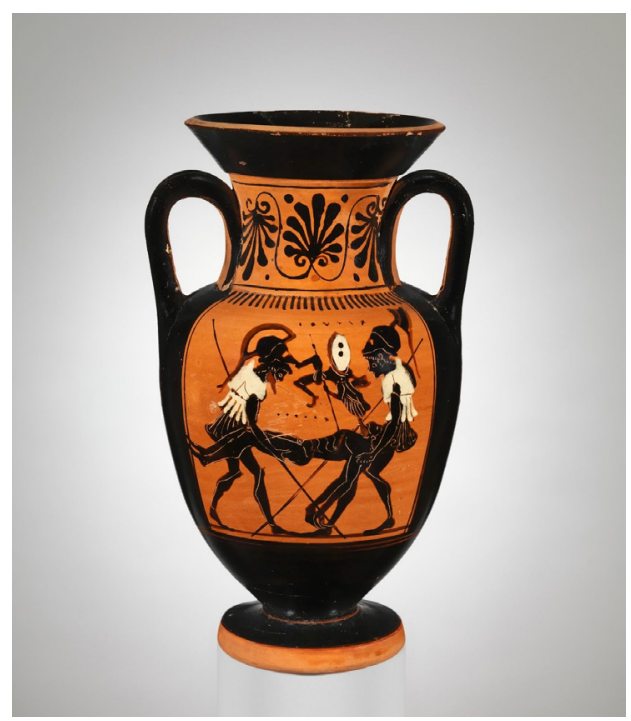

Figura 5

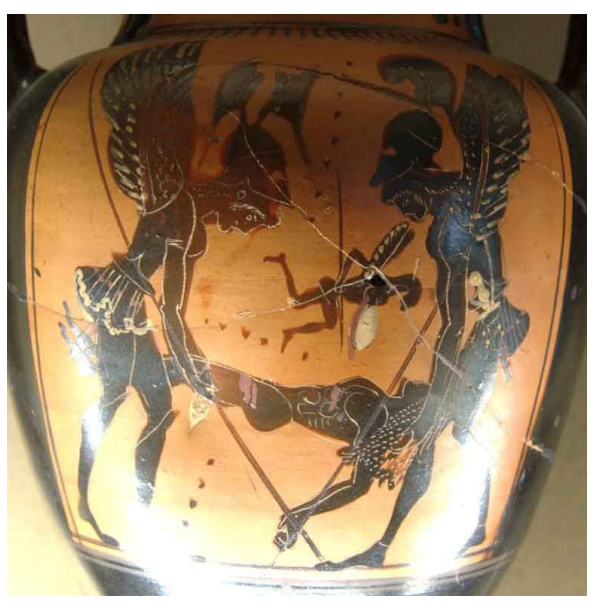

Figura 6 


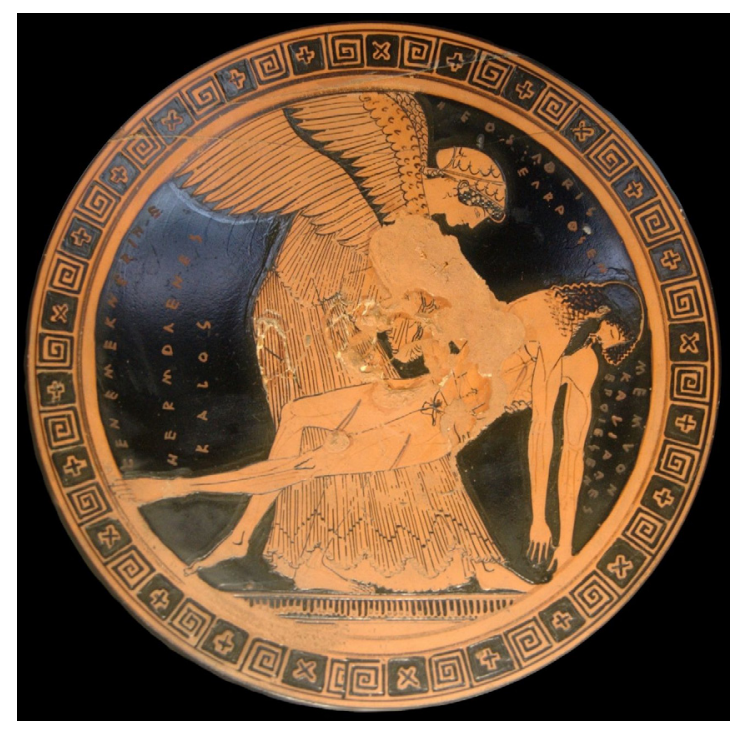

Figura 7

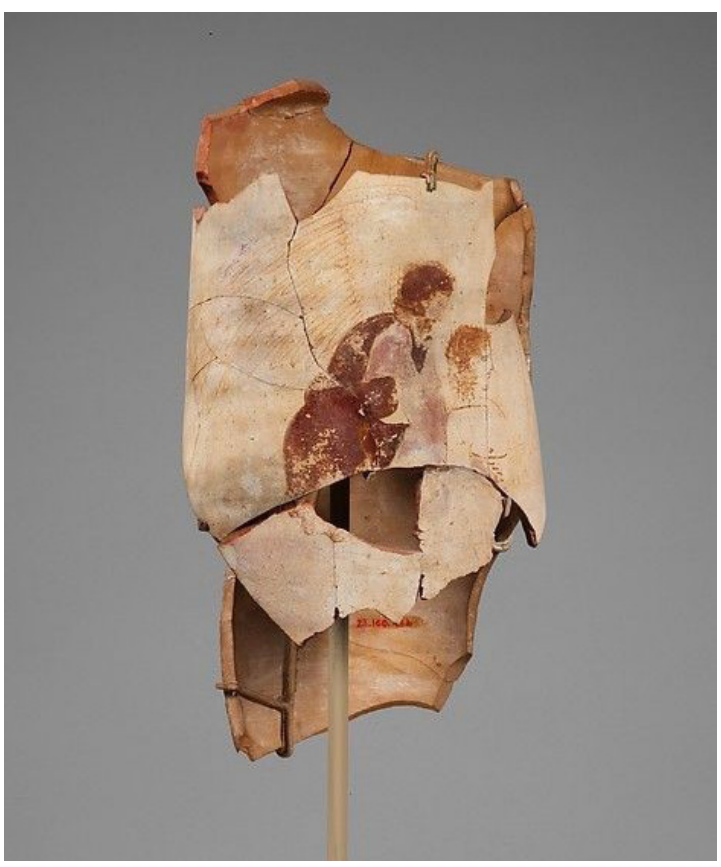

Figura 8

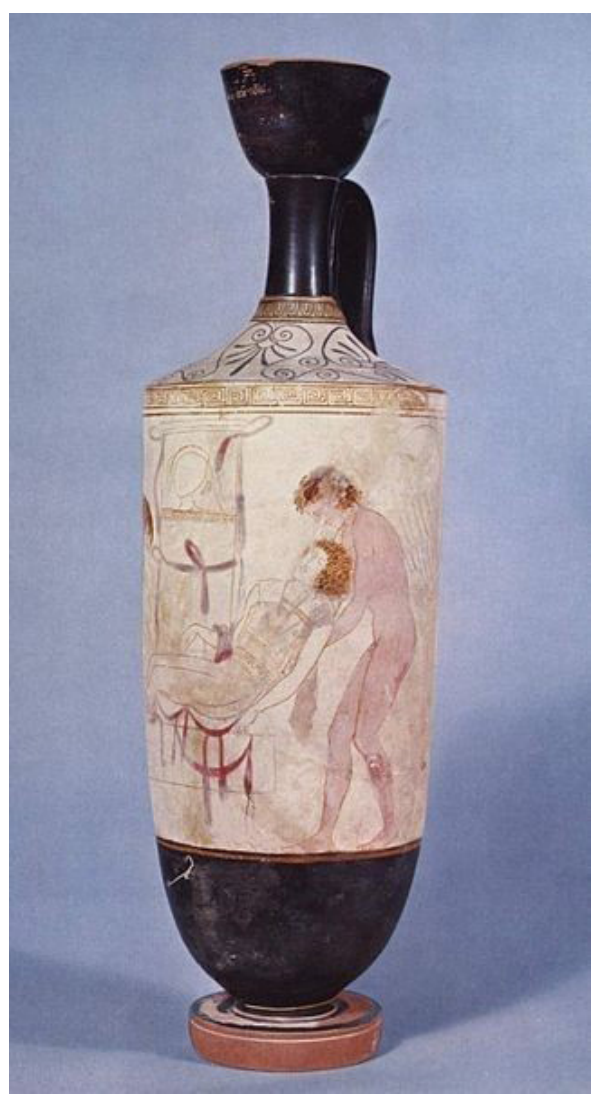

Figura 9 a

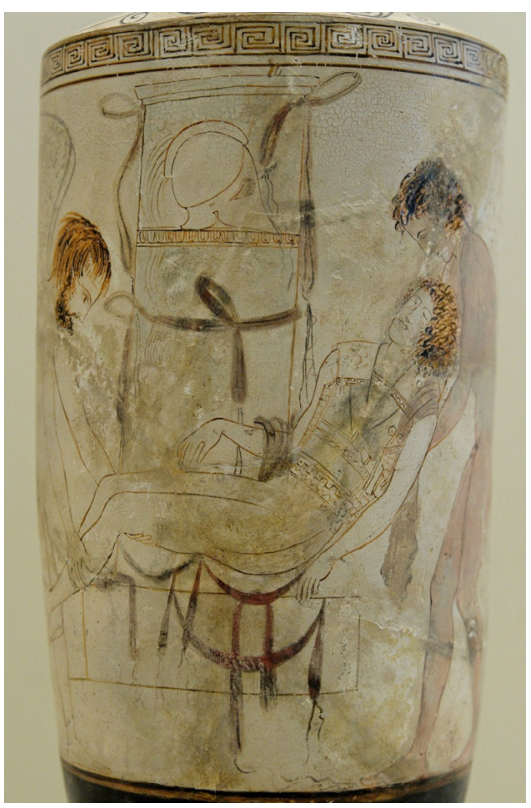

Figura $9 b$ 


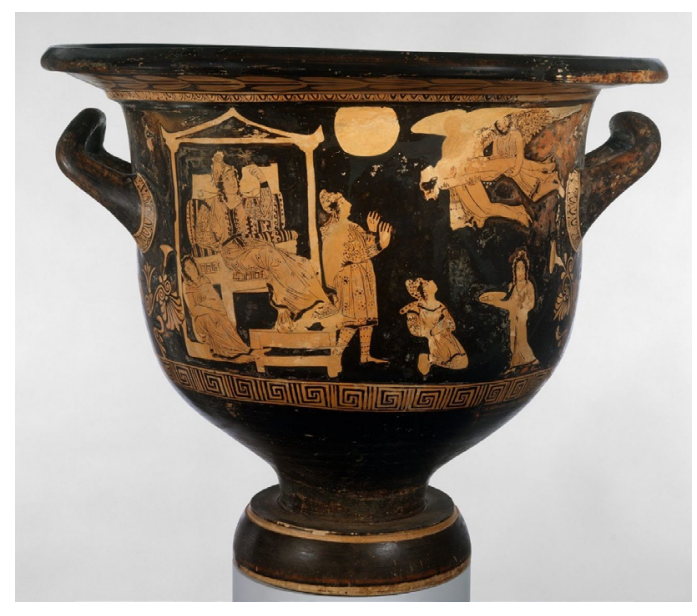

Figura 10 a

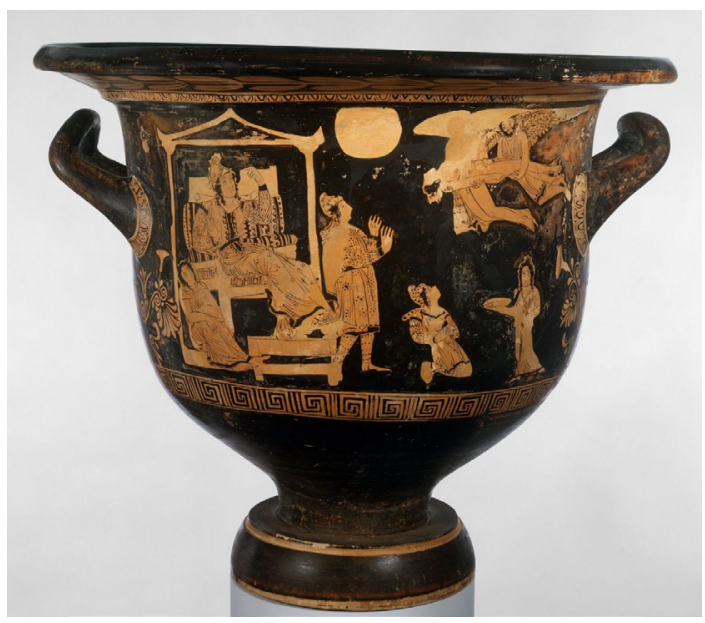

Figura $10 \mathrm{~b}$

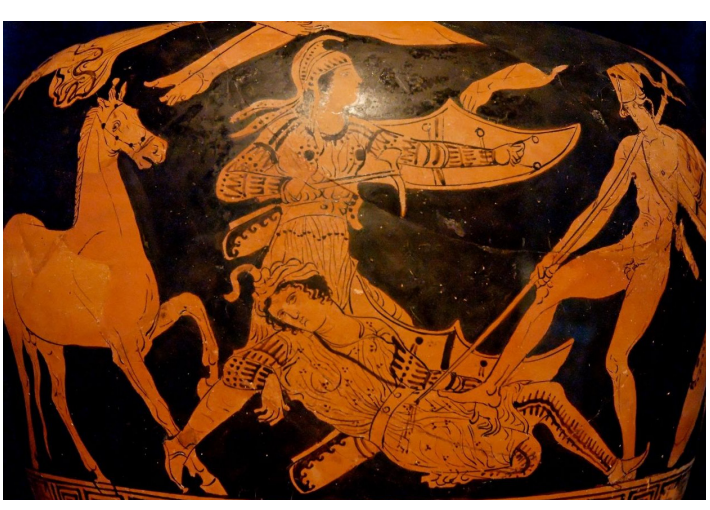

Figura 11

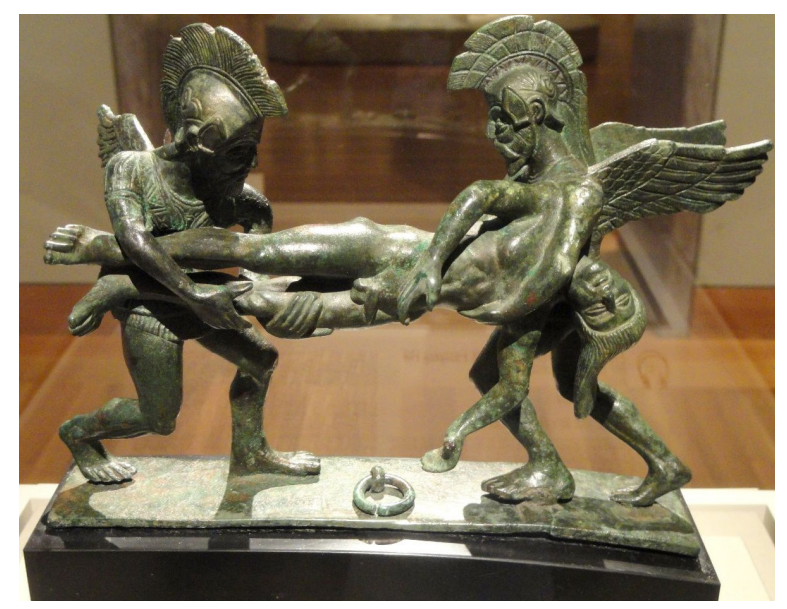

Figura 12

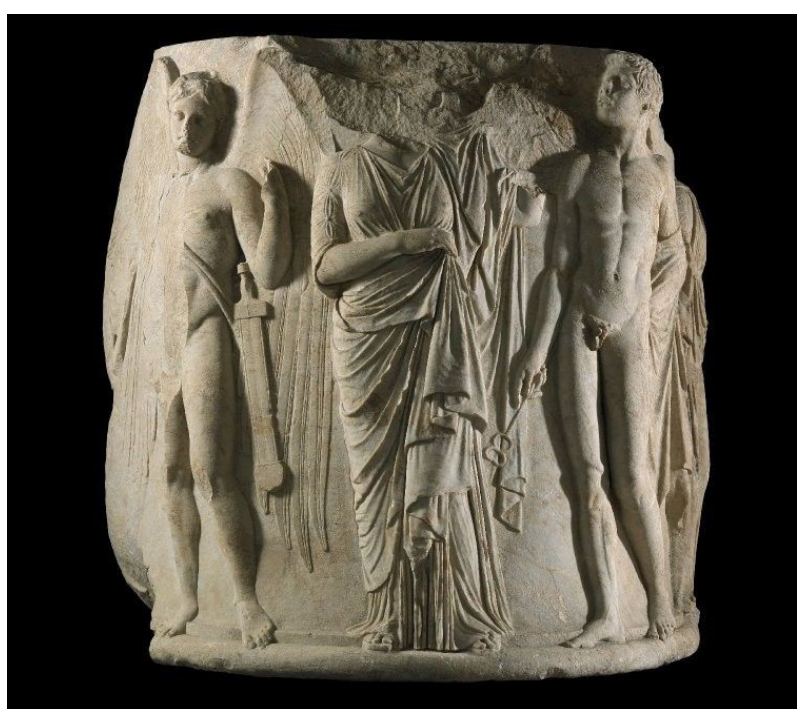

Figura 13

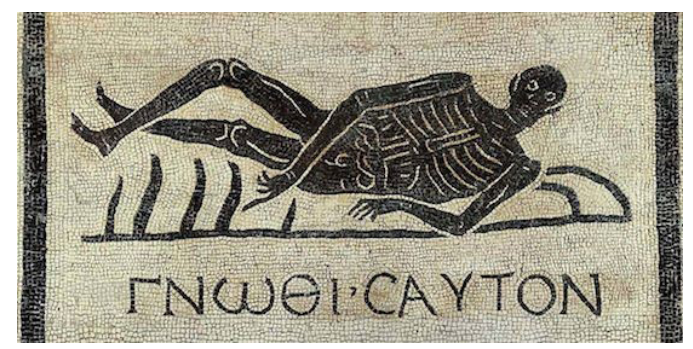

Figura 14 a 


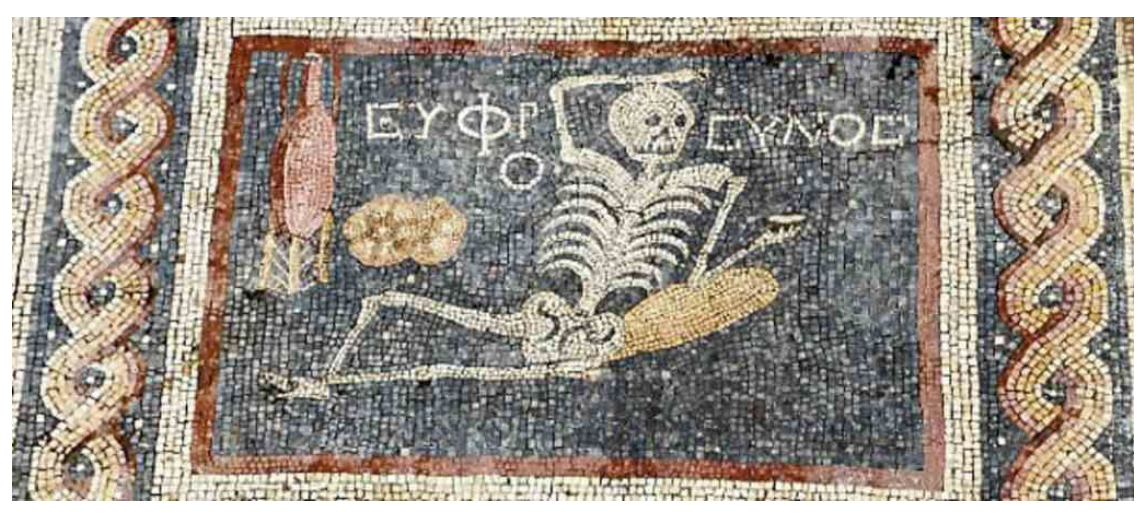

Figura $14 b$ 